\title{
Empowering employees with chronic diseases: process evaluation of an intervention aimed at job retention
}

\author{
Inge Varekamp • Boudien Krol · Frank J. H. van Dijk
}

Received: 12 November 2009 / Accepted: 1 September 2010 / Published online: 17 September 2010

(c) The Author(s) 2010. This article is published with open access at Springerlink.com

\begin{abstract}
Purpose Employees with a chronic disease may experience work-related problems that contribute to the risk of job loss. We developed a group-based intervention programme aimed at clarifying problems, making these a subject of discussion at work, and realizing solutions. This process evaluation investigates the intervention's feasibility and the satisfaction of 64 participants in eight groups.

Methods Data were collected through process evaluation forms and self-report questionnaires.

Results The recruitment of participants was time-consuming. Highly educated women working in the service sector were overrepresented. The programme was administered as planned, although components were sometimes only discussed briefly, due to lack of time. Satisfaction with the overall programme among participants was high; it was perceived as effective and there were only three dropouts. In particular, the focus on feelings and thoughts about having a chronic disease was highly valued, as were the exchange of experiences and role-playing directed at more assertive communication.

Conclusions A vocational rehabilitation programme aimed at job retention is feasible and is perceived to be effective. Such a programme should address psychosocial
\end{abstract}

I. Varekamp $(\varangle) \cdot$ F. J. H. van Dijk

Coronel Institute of Occupational Health,

Academic Medical Center, University of Amsterdam, PO Box 22600, 1100 DD Amsterdam, The Netherlands e-mail: i.varekamp@amc.nl

\section{B. Krol}

Department of Health Sciences, Section of Social Medicine, Work \& Health, University Medical Center Groningen, University of Groningen, PO Box 196,

9700 AD Groningen, The Netherlands aspects of working with a chronic disease beside practical problems. The recruitment of participants is time-consuming. Cooperation with outpatient clinics is necessary in order to reach all groups of employees with a chronic disease that might benefit from job retention programmes. Trial registration: ISRCTN77240155

Keywords Process evaluation - Chronic disease . Vocational rehabilitation - Occupational health . Job satisfaction $\cdot$ Job retention

\section{Introduction}

Employees with chronic disease may be hampered in job performance. Physical, sensory or cognitive limitations, health complaints such as fatigue or pain, psychological distress or medical requirements may hinder the performance of work tasks or even lead to work disability (Lerner et al. 2000; Van Amelsvoort et al. 2002; Donders et al. 2007). Chronically ill employees themselves state that, apart from work accommodations, they need acceptance of having a disease, coping strategies and support from their supervisor in order to stay at work (Detaille et al. 2003). This suggests that vocational rehabilitation aimed at changing personal attitudes and improving personal skills, including communication skills, is needed.

We developed a theory-driven group training programme for employees with chronic disease who experience work-related problems. The programme provided participants with knowledge, skills and insight regarding their values and needs, and we called it an empowerment programme (Feste and Anderson 1995). It focused on solving work-related problems and aimed at job retention and maintenance and an increase in job satisfaction. 
In this article, we present a process evaluation of eight training courses with a total of 64 participants. A systematic process evaluation can tell us whether the intervention was feasible and describe potential barriers to its implementation. Furthermore, it may clarify how the intervention works and gives insight into factors that influence its effectiveness (Swanborn 2004; Baranowski and Stables 2000; Saunders et al. 2005; Jonkers et al. 2007). This knowledge, in turn, offers the possibility to improve the programme. The research questions for the process evaluation are:

- Did the recruitment go as planned?

- Was the target group reached?

- Did participants follow the programme as it was intended?

- Was the programme administered as intended?

- Was the programme tailored to the group of participants?

- Were participants satisfied with the program?

- Was the programme perceived as effective?

The Medical Ethics Committee of the Academic Medical Center in Amsterdam approved of the study idea, but deemed ethical review unnecessary because they did not perceive the study to be 'medical' research. The effectiveness of this intervention is studied with a randomized controlled trial (RCT) design. The results of the RCT will be published elsewhere (Varekamp et al. 2010).

\section{Set-up and contents of the training programme}

The training programme consisted of six three-hour sessions every 2 weeks and a seventh session 2 months after the sixth session. One trainer worked with eight participants. At two sessions, there was an actor present for practicing role-playing. To discuss personal problems and progress at more length, three individual consultations also took place, one at the beginning, one halfway through the training and one after the sixth session. The trainers were experienced in working with groups, had psychotherapeutic knowledge of the principles of rational emotive therapy (RET) and occupational psychology, and a basic understanding of chronic disease and its consequences. A pilot version of the programme was first developed and tested. The pilot version was adapted based on the trainers' experiences, the researcher's observations, a pre- and post-test questionnaire and interviews with the participants by telephone.

The programme had a stepwise approach: first, exploring and clarifying work-related problems; second, a focus on communication at work; and third, developing and realizing solutions. Work-related problems were clarified with the help of the 'Quality of work' model, which emphasizes the energizing or distressing influences of work tasks, social relationships at work, working conditions and work-home interference.

A seventy-page course book accompanied the training, and participants completed homework for every session. The sessions consisted of four to seven components, including discussion of the homework and preparations for the next session. Each session focused on one theme:

1. Exploration and clarification of practical and psychosocial work-related problems with the help of the model 'Quality of work;'

2. Insight into feelings and thoughts about having a chronic disease and how these may influence communication;

3. Communication in daily work situations: theory and role play with an actor;

4. Practical matters: the occupational physician, the employment expert, legislation and facilities for disabled employees;

5. Communication and assertiveness: theory and role play with an actor;

6. A SMART plan to solve problems; and

7. Follow-up: what works and what does not.

Participants were eligible for the intervention if they had a chronic physical disease, had a paid job, experienced problems at work and feared losing their job or job satisfaction. Workers with predominant psychiatric conditions were excluded; people with a chronic physical disease in combination with depression were not excluded. Workers on long-term full sick leave that was expected to extend into the following months were excluded. The candidates themselves had to apply to the programme by telephone, also when they were referred by medical professionals. The training programme was offered free of charge.

A comprehensive description of the set-up and contents of the training programme, its development and theoretical framework is published elsewhere (Varekamp et al. 2008), as well as a systematic review of interventions of the same kind (Varekamp et al. 2006).

\section{Methods}

The various elements of the process evaluation, their operationalisation and measurement are presented in Table 1 (Baranowski and Stables 2000; Jonkers et al. 2007). The researcher recorded all recruitment activities and attended the first two training courses. The trainers completed a structured process evaluation form after each group session. Specific barriers or other observations could be noted on the form, in addition to the structured items. Participants filled in a questionnaire at baseline, and again after 4, 8, 12 and 24 months. Medical data were obtained from these 


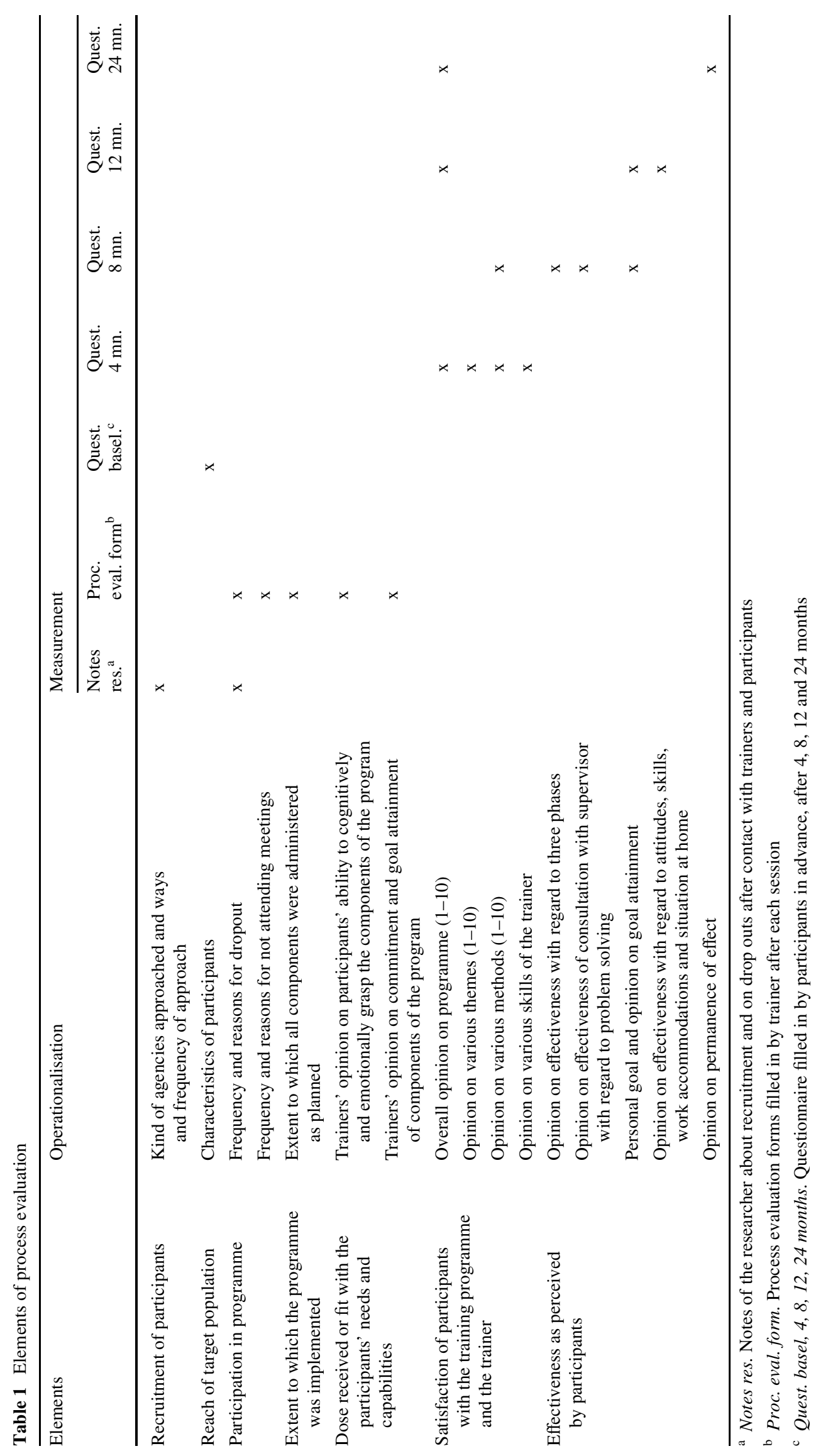


self-report questionnaires. Opinions about the importance of several themes, satisfaction with various methods used in the training and overall satisfaction were measured on a 1-10 scale. Participant opinions of the trainers' capacities were assessed with an adapted version of the "satisfaction with occupation rehabilitation" instrument by De Buck et al. (2004), consisting of six subscales: expertise (2 items), advice given (4 items), friendly treatment (3), personal attention (3), usefulness of programme (2) and information about programme (2). All items were 5-point Likert items.

The Medical Ethics Committee of Academic Medical Center in Amsterdam approved the study design and deemed ethical review unnecessary due to the non-medical nature of the research. All participants signed informed consent.

\section{Results}

\section{Recruitment of participants}

Participants were recruited for the training programme and study from late spring 2006 to January 2008. Participants were recruited via outpatient clinics, occupational health services, patient organizations, companies and so on. Presentations were given to patient organizations, doctors, nurses and social workers in outpatient clinics, professionals at occupational health centres and to a national conference on chronic diseases. In addition, mailings were sent to several large companies and one patient organization sent a recruitment mailing to their members. Advertisements were published in patient organization magazines, electronic newsletters and/or websites, in staff magazines at large companies and in magazines from an occupational health centre. About 3,500 paper leaflets were distributed via outpatient clinics, an occupational health centre and a patient information centre. A digital leaflet was available on several websites. It is difficult to assess the relative success of the various recruitment strategies, as we had no reports of the actions of medical professionals after hearing our presentations or reading about the project. Advertisements in patient organization magazines and/or electronic newsletters were successful. Presentations at outpatient clinics were seldom successful; when they were, it was due to interested nurses who advised patients to contact us. Contacts with occupational health services were moderately successful. Contacts with companies were successful if they paid attention to the project in the staff magazine. Table 2 presents figures on the sources of information about the project that the participants encountered (control group included). Recruitment took considerably more time than expected; we estimate roughly that it took $8-10$ months of full-time effort for one person to complete. These efforts
Table 2 Source of information about the training programme for the participants of the study (training participants and controls)

\begin{tabular}{lr}
\hline Sources of information & $\%$ \\
\hline Patient organization: magazine, presentation, & 34 \\
$\quad$ website, mailing & \\
Companies: house organ or supervisor & 21 \\
Occupational health service & 20 \\
Outpatient clinic & 13 \\
Conference on chronic diseases: magazine & 7 \\
$\quad$ or presentation & \\
Other & 10 \\
\hline
\end{tabular}

More than one answer was possible $(n=122)$

netted 122 of the planned 128 participants. One of the reasons for recruitment problems, according to some professionals of outpatient clinics and occupational health services, was that these professionals felt restrained from referring persons to the project because of the possibility of randomization to the control group (personal communications to IV). Another possible reason was that occupational physicians were afraid to 'lose' patients when they referred them to the training programme (personal communication to $\mathrm{FvD}$ ).

\section{Reach of target population}

The personal, work and medical characteristics of the participants of the programme are presented in Table 3. Mean age was 46 years, most participants were women, and highly educated people were over-represented. Mean disease duration was 10 years and almost half had more than one chronic disease. Musculoskeletal, digestive and neurological disorders comprised about three-quarters of the group. Fourteen per cent had categories of diseases, such as renal failure, poor eyesight, HIV and chronic fatigue syndrome. The great majority of the participants worked in the commercial or non-commercial service sector, for $30 \mathrm{~h}$ weekly, on average.

Participation in the programme

From November 2006 to March 2008, eight training courses took place, including three trainers and 64 participants in total. Two of the trainers gave three courses each and the third gave two courses. Three participants withdrew halfway, one due to medical treatment that interfered and two because they were not satisfied with the programme. There were 56 group sessions in total. Overall, there were 55 missed sessions, but in the majority of cases, participants called to say they were unable to attend. The reason most mentioned was illness. Three individual consultations took place with all participants who finished the programme. Forty-eight per cent participated in the training 
Table 3 Personal, medical and work characteristics of the training programme participants $(n=64)$

\begin{tabular}{ll}
\hline & $\begin{array}{l}\text { Mean } \\
\text { (SD) or \% }\end{array}$ \\
\hline Age & $46.1(8.8)$ \\
Women & 83 \\
Living alone (not with partner, children or parents) & 33 \\
Education & \\
Lower & 3 \\
Middle & 36 \\
Higher & 61 \\
Chronic disease ICD Classification & \\
1. diseases of the musculoskeletal system & 28 \\
and connective tissue & \\
2. diseases of the nervous system & 20 \\
3. diseases of the digestive system & 17 \\
4. endocrine, nutritional and metabolic diseases & 3 \\
5. neoplasms & 11 \\
6. diseases of the respiratory system & 2 \\
7. diseases of the circulatory system & 5 \\
8. diseases not otherwise specified & 14 \\
Disease duration in years & $10.2(9.6)$ \\
An additional chronic disease \% (co morbidity) & 48 \\
Branch of industry & \\
Agriculture and fishing & 0 \\
Industry and building industry & \\
Commercial services & \\
Non-commercial services & \\
Appointment & 30 \\
Hours per week & \\
\hline & \\
\hline
\end{tabular}

programme during working hours, $31 \%$ used days off and $20 \%$ combined these.

Extent to which the programme was implemented

Generally, all the planned components of the sessions were discussed, although some only briefly because of lack of time. One trainer mentioned that explaining the model 'Quality of work,' which emphasizes energizing and fatiguing or distressing factors, took too much time. Another trainer observed that the participants preferred to have time to exchange experiences with each other rather than listen to theoretical explanations, which they felt they could read in the course book. When discussing homework, it was often not possible to discuss each participant's work. When discussing work-related problems in the group using the 'Quality of work' model, only one instead of the planned two participants was often discussed. It was often impossible to have all participants practice role-playing in one session. One of the reasons was that discussing role-playing afterwards took a lot of time.

Dose received or fit with the participants' capabilities and needs

According to the trainers, participants had rarely cognitive difficulties with understanding the various components of the training. One thing that some people found difficult to grasp was reflection on their work in terms of subjective perceptions instead of objective facts. Slight or more severe emotional difficulties were met when discussing the consequences of having a chronic disease, feelings and thoughts on having a chronic disease and practical matters. Participation in the groups by individuals was usually high. The session components' aims were almost always 'fairly' or 'completely' achieved. Homework was generally completed by participants. One homework exercise presented difficulties for several participants; they were asked twice in the course of the programme to arrange a consultation with their supervisor. The first session was intended to be a discussion of how the supervisor judged their work performance, the second to discuss work-related problems and solutions. This exercise encountered resistance. Participants tended to delay the consultations and some did not complete them. Some participants said that it was 'pointless,' because of their supervisor's attitude, or they wanted to practice such a consultation beforehand in order to be prepared (see also last paragraph of the results section).

Satisfaction of the participants with the programme

The participants were asked to score how important the sessions' themes were for them on a 1-10 scale (Table 4). The themes 'Insight into feelings and thoughts about having a chronic disease' (session 2) and 'Communication and assertiveness' (sessions 3 and 5), were valued highest, with a mean score of 8.0. The theme 'Exploration of practical and psychosocial work-related problems,' which included the explanation of the model 'Quality of work' (session 1), scored 7.6. The theme of the sixth session, developing a 'SMART' personal plan, scored 7.5. 'Practical matters; the occupational physician, the employment expert, legislation and facilities for disabled employees' was evaluated as lowest, with a mean score of 7.0, and a high standard deviation. The training programme as a whole was evaluated with a mean score of 8.1 immediately after completion; this dropped 0.2 points 8 months later and 0.3 points 24 months later.

Eighty-six per cent of the participants always read the short introductions in the course book to prepare for the group sessions, whereas $95 \%$ had read the entire course book at the end of the training course. The course book was 
Table 4 Opinion of the training programme participants on the overall training programme, significance of themes, course book and methods $(n=64)$

\begin{tabular}{|c|c|}
\hline & $\begin{array}{l}\text { Rating (1-10) } \\
\text { Mean (SD) }\end{array}$ \\
\hline \multicolumn{2}{|l|}{ Overall training programme } \\
\hline Opinion after 4 months & $8.1(1.1)$ \\
\hline Opinion after 12 months & $7.9(1.1)$ \\
\hline Opinion after 24 months & $7.8(1.3)$ \\
\hline \multicolumn{2}{|l|}{ Themes } \\
\hline $\begin{array}{l}\text { Exploration and clarification of practical and psychosocial problems; } \\
\text { Quality of work model (session 1) }\end{array}$ & $7.6(1.7)$ \\
\hline Insight into feelings and thoughts about having a chronic disease (session 2) & $8.0(1.4)$ \\
\hline Communication in daily work situations and standing up for oneself (sessions 3 and 5) & $8.0(1.4)$ \\
\hline $\begin{array}{l}\text { Practical matters; the occupational physician, the employment expert, } \\
\text { legislation and facilities for disabled employees (session 4) }\end{array}$ & $7.0(2.0)$ \\
\hline A SMART plan to solve problems (session 6) & $7.5(1.7)$ \\
\hline The course book & $7.9(1.2)$ \\
\hline \multicolumn{2}{|l|}{ Methods } \\
\hline Theory explanation & $7.2(1.6)$ \\
\hline Exchanging experiences & $8.3(1.4)$ \\
\hline Filling in and discussing 'Quality of work' model & $7.5(1.2)$ \\
\hline Discussing others' 'Quality of work' model & $7.7(1.5)$ \\
\hline Role play with actor & $8.1(1.6)$ \\
\hline Questioning occupational physician and employment expert & $7.1(1.7)$ \\
\hline Having a consultation with the supervisor (homework) ${ }^{\mathrm{a}}$ & $7.2(1.9)$ \\
\hline Having a consultation with an occupational physician (homework) ${ }^{b}$ & $6.7(2.2)$ \\
\hline Individual consultation with trainer halfway & $7.9(1.4)$ \\
\hline Individual consultation with trainer at the end & $7.9(1.2)$ \\
\hline
\end{tabular}

Including opinion of three persons that dropped out halfway

${ }^{\text {a }}$ Low response, $n=57$

b Low response, $n=49$

rated with an average score of 7.9. Most valued were the chapters on communication and assertiveness, and on feelings and thoughts about having a chronic disease. Lowest valued, with the highest standard deviation, was the chapter on legislation and work accommodations.

A variety of methods was used in the training programme: theoretical explanation, exchange of experiences, role-playing, and homework, such as completing the model 'Quality of work', or arranging a consultation with a supervisor and occupational physician. The exchange of experiences among participants received the highest mean score among these. Role-playing and seeing and discussing others' role-playing was also highly appreciated, as were the individual consultations with the trainers. Less valued were arranging a consultation with a supervisor and with an occupational physician. Non-response on these two questionnaire items was high, 7 and 15 , respectively, which indicates that these arrangements not always took place.

The expertise of the trainers was overall judged very positively (mean score 68 on a $16-80$ scale), and the advice given by the trainers was felt to be helpful. The participants felt well-treated and felt that they received personal attention during the programme. They considered introductory information to be sufficient, although this could have been better for a minority. The three trainers were judged almost equally. Satisfaction with the trainers was not lower in the three groups in which the trainers acted for the first time, when compared to the five groups for which trainers were more experienced.

Effectiveness as perceived by the participants

The training programme used a stepwise approach: first exploring and clarifying work-related problems, then focusing on communication at work, and finally working on developing and realizing solutions. Eight months after the start, $84 \%$ of the participants found that the first phase worked well, while $69 \%$ found that the second phase and $65 \%$ found that the third phase worked well (Table 5). 
Table 5 Success of three steps of the training programme, as perceived by the training programme participants after 8 months $(n=64)$

\begin{tabular}{llllll}
\hline & & $\begin{array}{l}\text { Not successful } \\
\text { at all \% }\end{array}$ & $\begin{array}{l}\text { A little } \\
\text { successful \% }\end{array}$ & $\begin{array}{l}\text { Amply } \\
\text { successful \% }\end{array}$ & $\begin{array}{l}\text { Completely } \\
\text { successful \% }\end{array}$ \\
\hline 1 & Clarifying bottlenecks (Model 'Quality of work') & 0 & 16.4 & 55.7 & 27.9 \\
2 & Discussing bottlenecks at work & 3.3 & 27.9 & 45.9 & 23.0 \\
3 & Developing and realizing solutions & 6.7 & 28.3 & 45.0 & 20.0 \\
\hline
\end{tabular}

Table 6 Effect of training programme on work as perceived by the training programme participants after 12 months $(n=64)$

\begin{tabular}{llllll}
\hline Effect training on ... & $\begin{array}{l}\text { Large negative } \\
\text { effect }\end{array}$ & $\begin{array}{l}\text { Small negative } \\
\text { effect }\end{array}$ & $\begin{array}{l}\text { No } \\
\text { effect }\end{array}$ & $\begin{array}{l}\text { Small positive } \\
\text { effect }\end{array}$ & $\begin{array}{l}\text { Large positive } \\
\text { effect }\end{array}$ \\
\hline How I experience my disease and my work & 0 & 3.3 & 11.7 & 48.3 & 36.7 \\
How I deal with my disease and my work & 0 & 3.3 & 8.3 & 45.0 & 43.3 \\
How I discuss matters at work & 0 & 1.7 & 26.7 & 41.7 & 30.0 \\
How I deal with my supervisor & 0 & 0 & 23.3 & 51.7 & 25.0 \\
How I deal with my colleagues & 0 & 0 & 28.3 & 56.7 & 15.0 \\
How my supervisor deals with me & 0 & 0 & 38.3 & 43.3 & 18.3 \\
How my colleagues deal with me & 0 & 0 & 41.7 & 38.3 & 20.0 \\
The situation at home & 0 & 0 & 43.3 & 30.0 & 26.7 \\
Accommodations of my workplace or work tasks & 1.7 & 1.7 & 53.3 & 26.7 & 16.7 \\
\hline
\end{tabular}

The majority of the participants, 53 persons, had, as part of the training, discussed matters with their supervisor in order to find a solution for work-related problems. Fiftythree per cent of them felt this contributed a great deal to solving problems, $40 \%$ said that it contributed somewhat, whereas $6 \%$ said that it did not contribute and $2 \%$ felt these discussions had worked negatively.

Table 6 presents the effects of the programme on various aspects of working with a chronic disease, as perceived at 12 months follow-up. The participants noticed positive effects most often with regard to how they experienced and dealt with disease and work. This was followed by how matters at work were discussed and how they dealt with the supervisor and colleagues. An effect was noticed least often in work accommodations. After 24 months, $79 \%$ perceived a lasting effect of the training programme, $10 \%$ perceived an effect that had faded away, $3 \%$ were not sure whether it had lasted, and $8 \%$ perceived none or only a limited effect.

In the course of the programme, the participants formulated a plan of action with one or more personal goals. These goals related to work-home interference (78\%), feelings and thoughts about having a chronic disease (59\%), communication at the workplace $(44 \%)$, leisure time $(33 \%)$, work accommodations (29\%) or other topics (18\%). One year after the start of the programme, 6 per cent felt that they had not reached the goal that they set in the course of the programme, 38\% reached it 'a little,' $36 \%$ reached it amply and $20 \%$ completely.

\section{Discussion and conclusion}

The recruitment for this intervention yielded enough participants but was time-consuming. We enrolled a sample in which higher-educated women working in the service sector are over-represented. The majority of the participants were satisfied with the programme, and only a few dropouts were noted. For the most part, the programme was administered as planned, although some components took too much time. 'Quality of work' models and/or homework were not always discussed and not everybody had the opportunity to do role-playing as planned. The participants had no or only minor difficulties with understanding the materials discussed, but were more often emotionally upset, particularly when consequences of disease or feelings and thoughts were discussed, or during role-playing. Generally, the participants completed their homework, but when asked to organize a consultation with their supervisor, many hesitated to do so; a minority did not complete this assignment. Among those who completed these consultations, most considered it effective for problem solving. The perceived effectiveness of the training programme was highest in how it shaped participants' personal attitudes and lowest in matters that are more practical.

We have to be careful with conclusions based on the study process evaluation forms. The forms were completed by the trainers themselves and were likely correct as far as objective facts are concerned. The validity of some answers may be 
questionable, however, as trainers gave subjective judgments on whether the programme's components were tailored to the participants. Furthermore, they give an overall response for the whole group, rather than individuals. However, the forms are of special value when the three trainers showed consensus on less positive aspects or when they noted barriers. For instance, there was consensus on the lack of time for some components, all three observed that some components are likely to raise emotional difficulties and all noted that consultations with the supervisor are often met with resistance.

Another weakness of this study is that we do not know what proportion of the target group was reached. We did not approach a known group of employees with chronic diseases. Instead, information about the project was disseminated through various channels and potential participants had to contact researchers to participate. The consequence is that we do not know how many employees who experience serious work-related problems were not interested in our programme or did not enrol for other reasons. We do know that the group we reached was a selected group in terms of socio-demographic characteristics.

What can we learn from the study results? We know that our programme is implementable, although we have to keep in mind that the majority in this study was highly educated. At some sessions, there was inadequate time for complete participation. Lengthening the duration of the sessions and adding sessions are options. However, this may make the programme too time-consuming. Reducing the time to discuss personal experiences is not an option. Because participants have three individual consultations with a trainer, and because lack of personal attention appeared not to be a problem, it is presumed to be better to accept this programme design but to indicate at the beginning of the sessions that not everyone may receive equal attention in all components of the programme. We found in the pilot phase that participants with a variety of chronic physical diseases could be put together in the same group. People experience the general aspects of chronic diseases as more important than the disease specifics. Finally, we learned that the theme 'Practical matters' was not highly valued by a quarter of the participants. It is worth considering whether this theme can be addressed in another way.

What are the working elements of the training programme? The trainers observed that many of the components raised emotional feelings, and it is interesting to note that these components were often highly valued. Apparently, many participants realized that going through a phase of mourning and learning to accept having a chronic disease is difficult, but it assists in learning to cope. This brings us to our assumption that participants needed to pass through three phases: clarifying, communicating and solving problems. We understood the earlier phases as necessary to accomplish the last essential phase and understood this final phase implicitly as organizing work accommodations. However, it appears that organizing work accommodations may be the primary problem for some persons; for others, the main problem is in the earlier phases of accepting the chronic disease and learning to communicate about it and/or in maintaining an enjoyable life outside work. These issues appear to be relevant for many participants and are therefore noteworthy.

Another remarkable phenomenon was that many participants showed resistance to a consultation with their supervisor, but in the end, the majority felt that it helped in solving problems. This shows, as we have seen in other studies (Detaille et al. 2003; Post et al. 2005), that a good relationship with the supervisor is very important. For future use, it is important to discuss with the participants that this consultation often is successful in the end, the more so when it is practiced beforehand with role-playing.

Recruitment for programmes like this is known to be problematic (Varekamp et al. 2006; Foster et al. 2007). One reason is the randomization procedure, but the fact that the majority of the participants needed to use days of might have played a part as well. Recruitment through professionals in outpatient clinics was problematic compared to recruitment with the help of patient organizations. Disseminating this kind of programme through normal health care channels appears not to work; lack of interest in workrelated problems among many health care professionals is a primary reason (Van Weel et al. 2006). Physicians and nurses should be encouraged in the course of their education and by post-graduate courses to pay attention to the working life of their patients; there is little chance for referral of patients to vocational rehabilitation programmes without conversations about these matters. It is positive that practice guidelines for physicians increasingly pay attention to work-related problems of patients. Maybe incentives like co-authorship of a scientific article may help to raise interest in this kind of research and development projects. In addition, focus on specialized nurses as collaborating partners may prove beneficial, as these professionals concentrate more on the social consequences of chronic disease.

Working together more intensively with outpatient clinics in the future would have the added advantage of contact with a more diverse group of potential participants. Heavy manual work and low education are prognostic factors for work disability among employees with chronic disease (Detaille et al. 2009). We do not know why we had only a few participants working in industry, and fewer men and less-educated people than expected. Research into whether similar communication-focused programmes are attuned to the culture and working conditions outside of the service sector is necessary. We need to know why less-educated people seldom applied for the study, as well as whether and 
how more men can be convinced to participate in empowerment programmes, which focus on sometimes emotionally disturbing topics.

Several vocational rehabilitation approaches aimed at job retention for people with chronic or longstanding disease have recently been developed, varying widely in approach. Multidisciplinary rehabilitation has been developed for patients with rheumatoid arthritis (De Buck et al. 2005). This is an outpatient clinic-based intervention where medical and psychosocial specialists combine their expertise in advising the patient and his or her occupational physician on aspects of work. A completely different approach is the participatory workplace intervention (Anema et al. 2007). This focuses on the employee and supervisor and aims to improve their ability to solve work-related problems with the help of a mediator. Our intervention aimed at improving the problem-solving skills of the employee. Every approach will have advantages and may be most effective in a specific context. More research is needed on what kind of rehabilitation method best suits a particular employee and circumstances. The extent to which employers are willing to accommodate the workplace to employees with a chronic disease or handicap also needs research.

We may conclude that empowering employees with a chronic disease with help of a group training programme is feasible and highly valued. For that reason, it should be offered in occupational health care or other health care settings.

Acknowledgments The development and realization of the intervention as well as the study are financially supported by the Dutch Ministry of Social Affairs and Employment and the Stichting Instituut Gak. The occupational health service provider ArboUnie supported the development and realization of the intervention.

\section{Conflict of interest None.}

Open Access This article is distributed under the terms of the Creative Commons Attribution Noncommercial License which permits any noncommercial use, distribution, and reproduction in any medium, provided the original author(s) and source are credited.

\section{References}

Anema JR, Steenstra IA, Bongers PM, de Vet HC, Knol DL, Loisel P et al (2007) Multidisciplinary rehabilitation for subacute low back pain: graded activity or workplace intervention or both? A randomized controlled trial. Spine 32(3):291-298

Baranowski T, Stables G (2000) Process evaluations of the 5-a-day projects. Health Educ Behav 27(2):157-166
De Buck PD, Breedveld J, van der Giesen FJ, Vliet Vlieland TP (2004) A multidisciplinary job retention vocational rehabilitation programme for patients with chronic rheumatic diseases: patients' and occupational physicians' satisfaction. Ann Rheum Dis 63(5):562-568

De Buck PD, le Cessie S, van den Hout WB, Peeters AJ, Ronday HK, Westedt ML et al (2005) Randomized comparison of a multidisciplinary job-retention vocational rehabilitation programme with usual outpatient care in patients with chronic arthritis at risk for job loss. Arthritis Rheum 53(5):682-690

Detaille SI, Haafkens JA, van Dijk FJH (2003) What employees with rheumatoid arthritis, diabetes mellitus and hearing loss need to cope at work. Scand J Work Environ Health 29:134-142

Detaille SI, Heerkens YF, Engels JA, van der Gulden JW, van Dijk FJ (2009) Common prognostic factors of work disability among employees with a chronic somatic disease: a systematic review of cohort studies. Scand J Work Environ Health 35(4):261-281

Donders NC, Roskes K, van der Gulden JW (2007) Fatigue, emotional exhaustion and perceived health complaints associated with work-related characteristics in employees with and without chronic diseases. Int Arch Occup Environ Health 80(7):577-587

Feste C, Anderson RM (1995) Empowerment: from philosophy to practice. Patient Educ Couns 26:139-144

Foster G, Taylor SJ, Eldridge SE, Ramsay J, Griffiths CJ (2007) Selfmanagement education programmes by lay leaders for people with chronic conditions. Cochrane Database Syst Rev (4):CD005108

Jonkers C, Lamers F, Bosma H, Metsemakers J, Kempen G, van Eijk J (2007) Process evaluation of a minimal psychological intervention to reduce depression in chronically ill elderly persons. Patient Educ Couns 68(3):252-257

Lerner DJ, Amick BC III, Malspeis S, Rogers WH (2000) A national survey of health-related work limitations among employed persons in the United States. Disabil Rehabil 22(5):225-232

Post M, Krol B, Groothoff JW (2005) Work-related determinants of return to work of employees on long-term sickness absence. Disabil Rehabil 27(9):481-488

Saunders RP, Evans MH, Joshi P (2005) Developing a process-evaluation plan for assessing health promotion programme implementation: a how-to guide. Health Promot Pract 6(2):134-147

Swanborn PG (2004) Evalueren (Evaluation). Uitgeverij Boom, Amsterdam

Van Amelsvoort LG, Kant IJ, Beurskens AJ, Schroer CA, Swaen GM (2002) Fatigue as a predictor of work disability. Occup Environ Med 59(10):712-713

Van Weel C, Orbon K, van der Gulden J, Buijs P, Folgering H, Thoonen $B$ et al (2006) Occupational health and general practice: from opportunities lost to opportunities capitalised? Med Lav 97(2):288-294

Varekamp I, Verbeek JH, van Dijk FJ (2006) How can we help employees with chronic diseases to stay at work? A review of interventions aimed at job retention and based on an empowerment perspective. Int Arch Occup Environ Health 80(2):87-97

Varekamp I, de Vries G, Heutink A, van Dijk FJ (2008) Empowering employees with chronic diseases; development of an intervention aimed at job retention and design of a randomised controlled trial. BMC Health Serv Res 8(1):224

Varekamp I, Verbeek JHAM, de Boer AGEM, van Dijk FJH (2010) Effect of a training programme aimed at job retention for employees with chronic diseases: a randomised controlled trial on selfefficacy, job satisfaction and fatigue (submitted) 